\title{
Role of Anti-Oxidants in the Treatment of Vitiligo
}

\author{
Kumar A', Agrawal S², Dhali TK ${ }^{3}$ Majhi SK ${ }^{4}$
}

${ }^{1}$ Department of Dermatology, CosmoDerma, Sumitra Sadan, Hinoo, Ranchi; ${ }^{2}$ Department of Dermatology \& Venereology, B. P. Koirala Institute of Health Sciences, Dharan, Nepal; ${ }^{3}$ Department of Dermatology \& Venereology, ESIC PGIMSR, Basaidarapur, New Delhi; ${ }^{4}$ Department of Biochemistry, Xavier University School of Medicine, Oranjestad, Aruba, Dutch Caribbean.

\begin{abstract}
Introduction: The role of free radicals and oxidative damage in the pathophysiology of vitiligo has been documented in recent studies. Antioxidant supplementation has been reported to be useful in the treatment of vitiligo.

Objective: To evaluate the role of oral antioxidants supplementation therapy in the treatment of vitiligo by assessing the onset of repigmentation and oxidative stress.

Materials and Methods: A total of 80 cases of vitiligo randomized into two groups: antioxidant and placebo comprising 40 patients each and were followed up for 8 weeks for the assessment of onset of repigmentation of vitiliginous lesions as primary outcome. The activities of Malondialdehyde (MDA), Vitamin C, and Vitamin E in serum and of Catalase (CAT) in erythrocytes of patients at baseline and at end of eight weeks were also assessed by using the spectrophotometric assay.

Results: The onset of repigmentation was noted significantly earlier among the anti-oxidant group as compared to the placebo group ( $p=0.015)$. At the baseline, between the two groups, no significant difference was found in the different biochemical parameters. However, at the end of 2 months the level of MDA $(p<0.001)$ was found to be significantly lower and that of Vitamin $E(p<0.001)$ and CAT $(p=0.005)$ was significantly higher among the anti-oxidants group as compared to the placebo group.

Conclusion: Antioxidant supplementation carried a better response in terms of early onset of repigmentation and significant decrease in the oxidative stress, in the short follow up of two months.

Key words: Anti-oxidants; Oxidative stress; Free radicals, Vitamins; Vitiligo
\end{abstract}

\section{Introduction}

$\mathrm{V}$ itiligo is a common, acquired depigmenting disorder that affects approximately $0.1-2 \%$ of world population. ${ }^{1}$ The etiopathogenesis is unknown, but involves the interplay of multiple factors: autoimmunity, neurologic factors, oxidative stress, and lack of melanocyte growth factors. ${ }^{2}$

The oxidative stress is postulated as a cause for vitiligo and as initial pathogenic event in melanocyte degeneration. ${ }^{3}$ Vitiligo patients have an imbalanced redox state of the skin, causing excess production and accumulation of reactive oxygen species (ROS, viz., $\mathrm{H}_{2} \mathrm{O}_{2}$ ), which have toxic effects on all components of the cell (viz., proteins, lipids), potentially resulting in melanocytes destruction. ${ }^{2-4}$

Address of Correspondence:

Dr. Amit Kumar

Consultant Dermatologist

CosmoDerma

Sumitra Sadan, Hinoo, Ranchi, India- 834002

E-mail: amitkr28@gmail.com
The majority of studies including ours germane to ROS model for the pathogenesis of vitiligo. ${ }^{2-5}$ Laddha and colleagues argue that vitiligo is caused by an oxidant/ anti-oxidant imbalance in the melanocyte, leading to creation of a neo-antigen and giving credence to a convergent terminal pathway of oxidative stressautoimmunity-mediated melanocyte loss. ${ }^{6}$

\footnotetext{
Submitted: $25^{\text {th }}$ August 2018

Accepted: $23^{\text {rd }}$ December 2018

Published: $31^{\text {st }}$ March 2019
}

\section{How to cite this article}

Kumar A, Agrawal S, Dhali TK, Majhi SK. Role of anti- oxidants in the treatment of vitiligo. Nepal Journal of Dermatology, Venereology and Leprology. 2019;17(1):49-57. doi: http:// dx.doi.org/10.3126/njdvl.v17i1.23132

\section{(i)}

Licensed under CC BY 4.0 International License which permits use, distribution and reproduction in any medium, provided the original work is properly cited. 
Since oxidative stress as a part of autocytotoxic theory has been proposed as a possible pathogenetic mechanism, antioxidant supplementation for treatment of vitiligo has been tried alone or in combination with phototherapy, although definitive clinical evidence of its efficacy is lacking. ${ }^{7-12}$ A systematic review investigated the efficacy of antioxidants for treatment of vitiligo and concluded a weak positive outcome with poor methodological quality and significant reporting flaws in the studies. ${ }^{13}$ Therefore, we undertook this study to evaluate the role of antioxidants supplementation in the treatment of vitiligo by assessing the onset of repigmentation and oxidative stress before and after the treatment.

\section{Materials and Methods}

\section{Patients}

This was a double-blind randomized placebo-controlled clinical trial of vitiligo patients visiting Dermatology outpatient department of B. P. Koirala Institute of Health Sciences (BPKIHS), Dharan over a period of one year. Patients with age $<15$ years, pregnant and lactating females, receiving any active systemic therapy within the previous four weeks for vitiligo or any systemic infections, or those who refused to give consent were excluded from the study. All participants completed an informed consent form prior to their enrolment in the study

Patients were allocated to treatment groups in a 1:1 ratio using a predetermined computer-generated randomization list by block size of four, six and eight with the help of www.sealedenvelope.com. An independent dermatologist provided the sequentially numbered list with treatment group written in a sealed envelope.

The detailed history including the clinical examination was performed in each patient and was recorded in a preset pro forma. The activities of Malondialdehyde $(\mathrm{MDA})^{14}$, Vitamin $\mathrm{C}^{15}$, Vitamin $\mathrm{E}^{16}$ in serum and Catalase $(C A T)^{17}$ in erythrocytes were assessed by using the spectrophotometric assay at the baseline and at two months.

The protocol of this study was approved by Institutional Ethics Committee of B. P. Koirala Institute of Health Sciences and informed written consents were obtained from all participants.

\section{Intervention}

The patients in the anti-oxidant group were given Vitamin A 25,000 IU, Vitamin E $400 \mathrm{IU}$, Vitamin C 1000 $\mathrm{mg}$, and Zinc $40 \mathrm{mg}$ once daily, whereas patients in the placebo group were given size and color matched sugar-coated tablets and jelly once daily for the treatment period of two months. The medicines were supplied to the patients in a plastic bottle.

The patients were asked to bring the empty bottle of oral drug supplementation to ensure that patients had been taking them regularly.

\section{Assessment and follow up}

The body surface area (BSA) involvement was assessed according to the rule of nine. During the course of study, vitiligo was clinically assessed fortnightly by a blinded assessor (dermatologist) to find the onset of repigmentation as well as the extent of repigmentation. Digital photographs of vitiliginous lesions were taken at baseline and at each follow up visits for objective assessments by an independent dermatologist.

Oxidative stress was assessed by measuring the activities of plasma MDA, Vitamin C, Vitamin E and erythrocyte CAT at the baseline and at two months and compared between the groups. The biostatistician, who analyzed the data was blinded too on details of each group.

\section{Evaluation of treatment efficacy and adverse effects}

Treatment efficacy was measured by assessing the proportion of patients that had onset of repigmentation at eight weeks as primary outcome at the baseline and at two months and also compared between the groups. Secondary outcomes were the extent of repigmentation, stabilization of disease process, oxidative stress and local and systemic adverse effects rate after the completion of therapy.

\section{Statistical analysis}

Statistics were performed by using SPSS software SPSS Version 10.0 for Windows, SPSS Inc, Chicago, IL). Mean, median, percentage and SD were used to describe the descriptive data. Appropriate statistical tool both parametric and non-parametric paired and unpaired two-sample t-test or Wilcoxon sign rank test and Wilcoxon rank sum test were used to analyze the correlation between different variables within and between the groups. Categorical variables were analyzed by $\mathrm{X}^{2}$ analysis of $2 \times 2$ contingency tables or by Fisher's exact test as appropriate, for differences within and between the groups. Time to event analyses was performed for the onset of repigmentation of vitiliginous lesion by using Kaplan-Meier method to account for truncated observation. We analyzed the difference between event curves by means of the log rank test. The differences were regarded as statistically significant, with an alpha error of 0.05 . Although a 
total of 39 patients were determined in each group in order to have $80 \%$ power for detecting the significant difference in the onset of repigmentation at eight weeks with oral antioxidants (62\%) and without treatment (30\%), hazard ratio 2.36 and two sided at 5\% alpha error, 40 patients in each group were recruited considering the drop out for the present study.

\section{Results}

\section{Patient Characteristics}

A total of 80 patients were included in the study and were randomized into two groups. All the patients completed the study. Figure 1 depicts the flow diagram of the participants in the study.
The baseline characteristic of the patients in both groups is summarized in Table 1 . There was no statistical difference in between the two groups.

\section{Outcome of Treatment \\ Comparison of onset of repigmentation}

The onset of repigmentation among the antioxidants group was between two to eight weeks with the median of four weeks, whereas among the placebo group onset of repigmentation was observed between three to eight weeks and the median was six weeks (Figure 2 and 3).

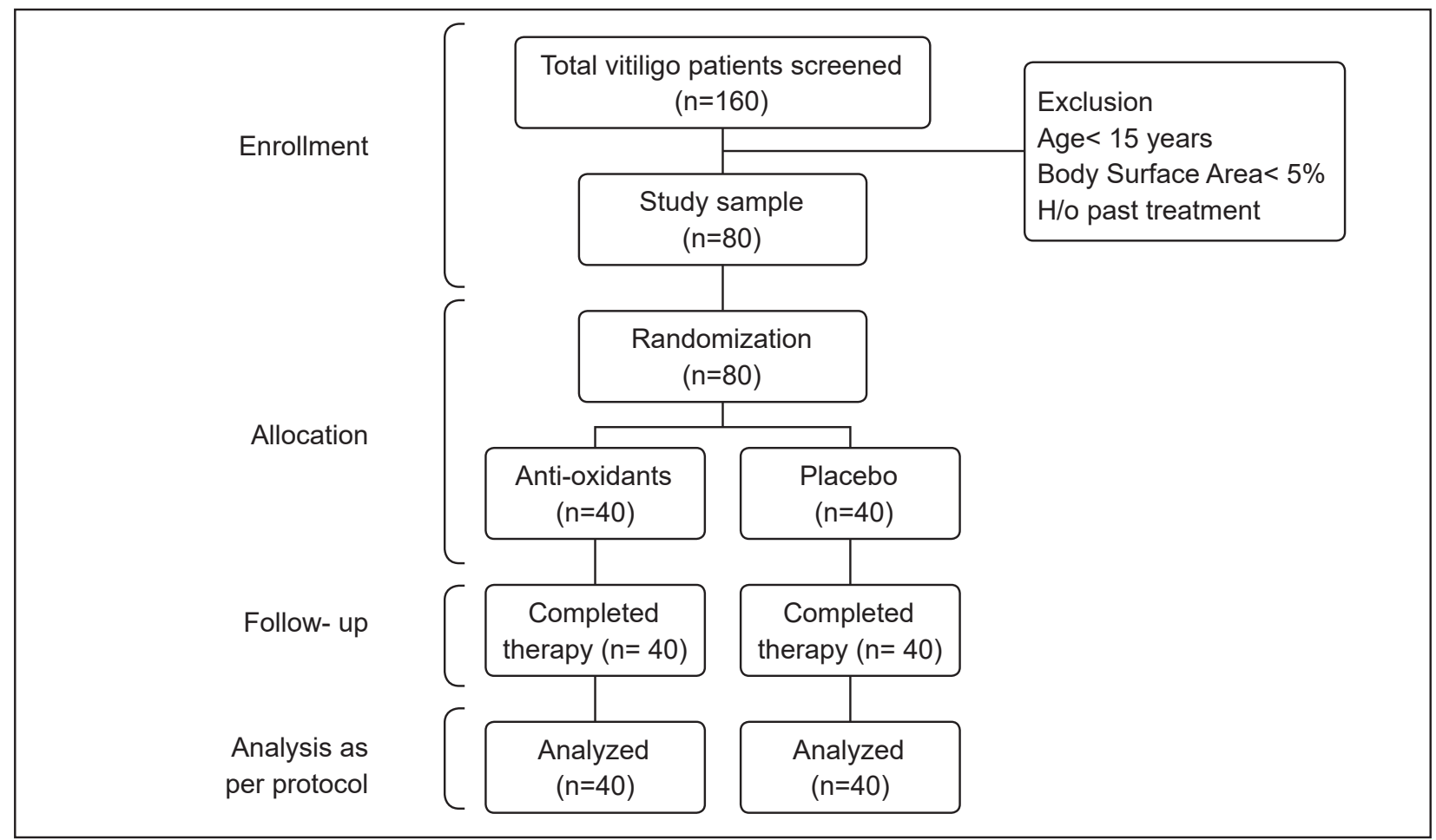

Figure 1: Flow diagram of the study population through different stages
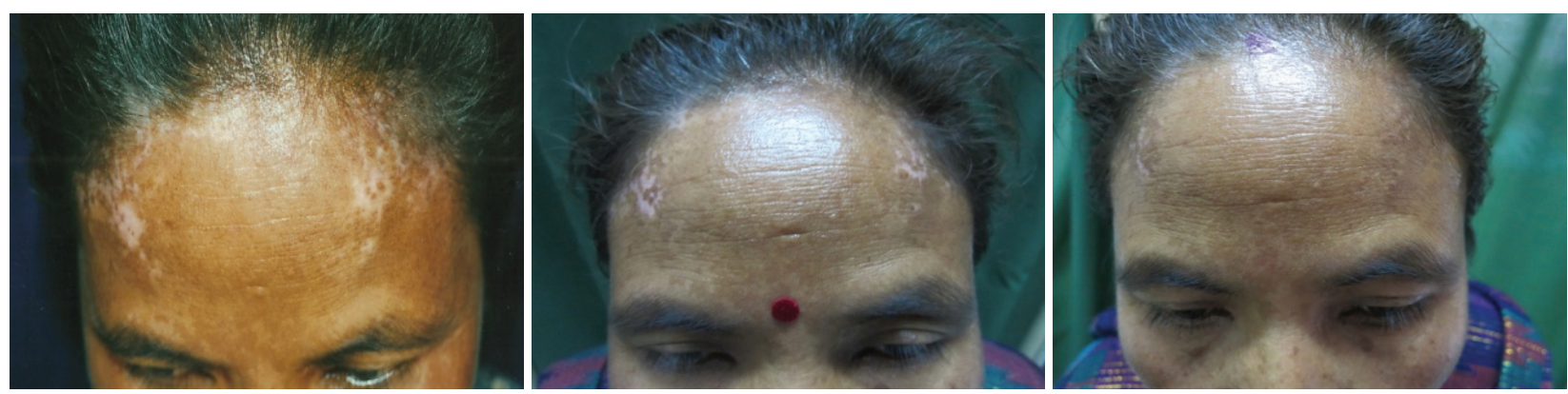

Figure 2: Patient with vitiligo received antioxidant. (a) at baseline, 4 weeks and after 8 weeks. 

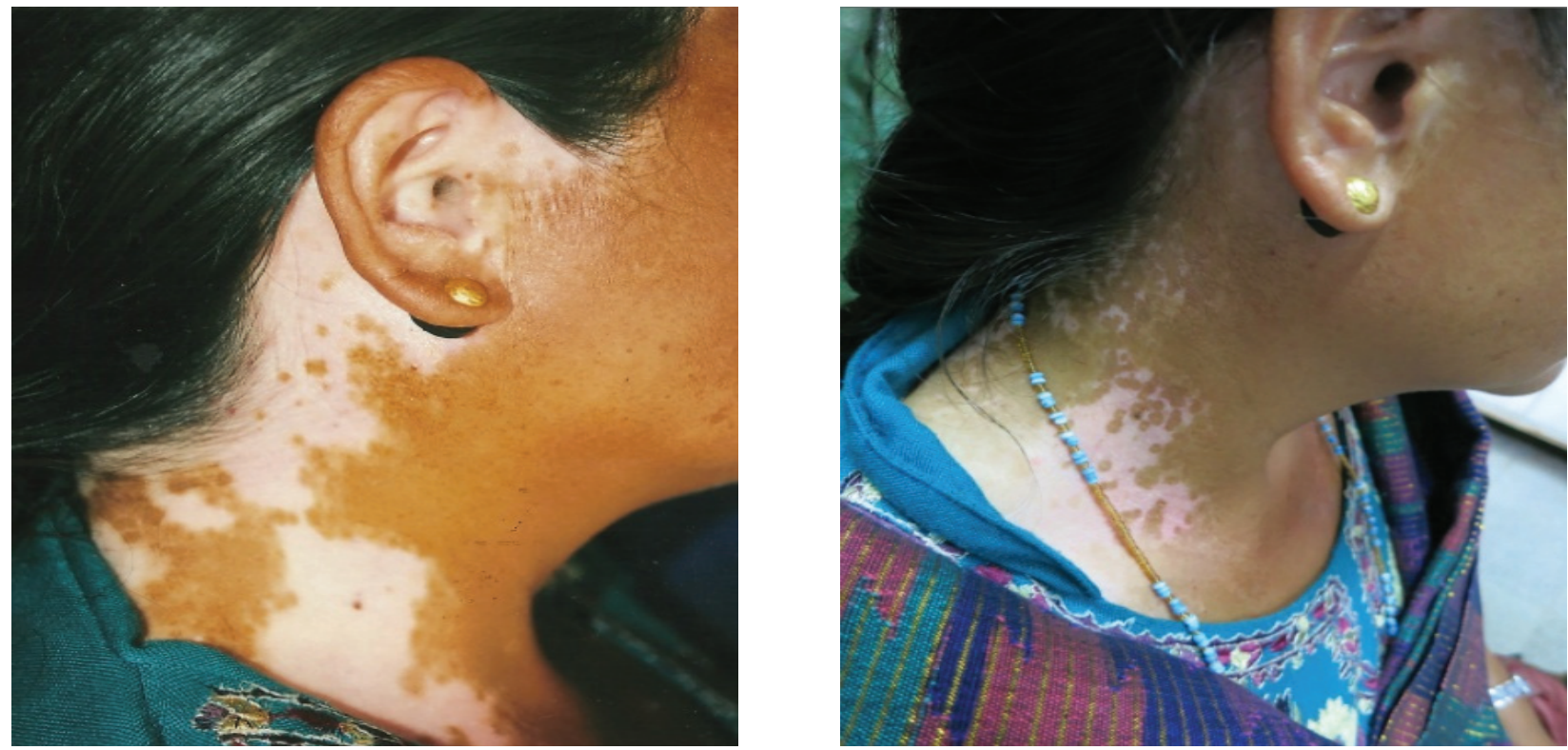

(b) at baseline and after 8 weeks.
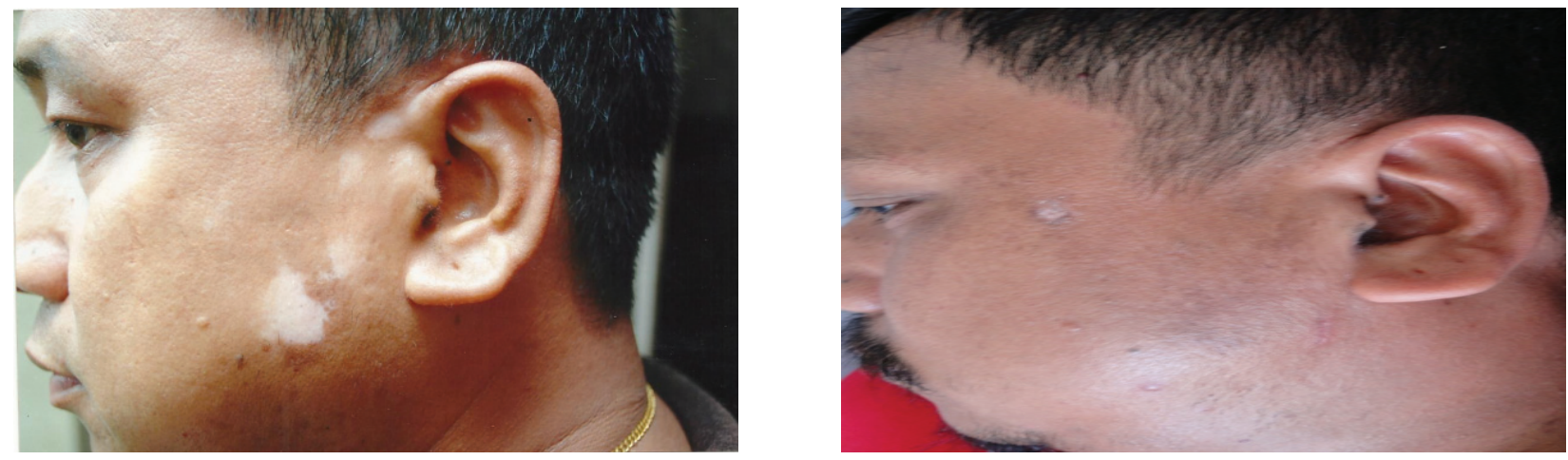

(c) at baseline and after 8 weeks.
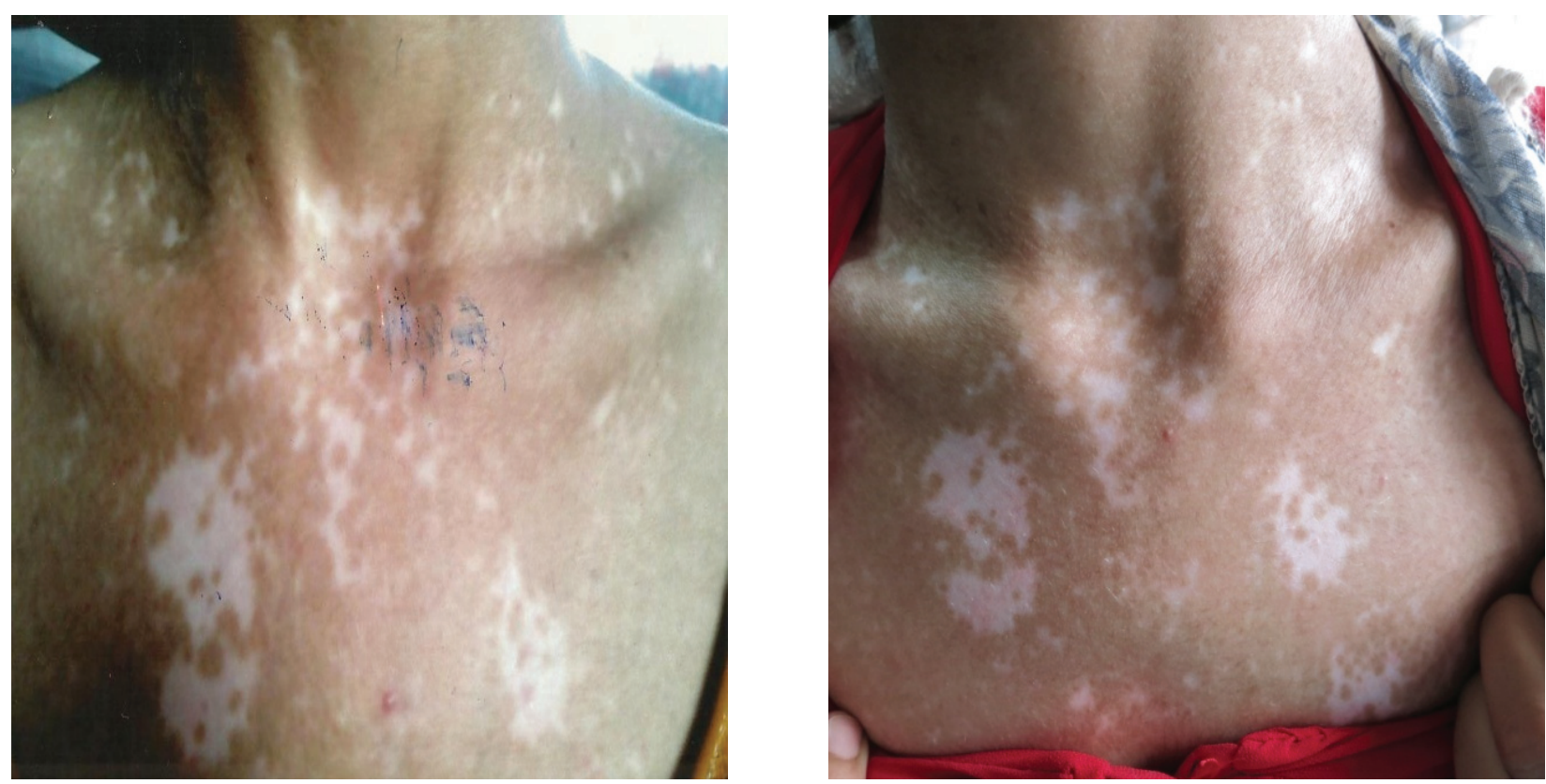

Figure 3: Patient in the placebo group (a) at baseline and after 8 weeks. 

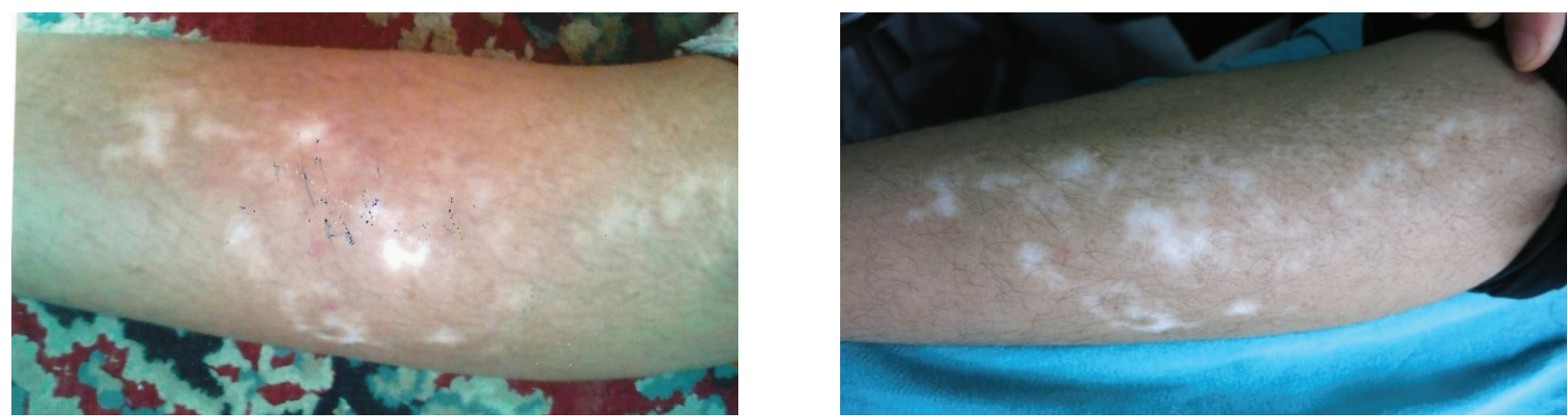

(b) at baseline and after 8 weeks.

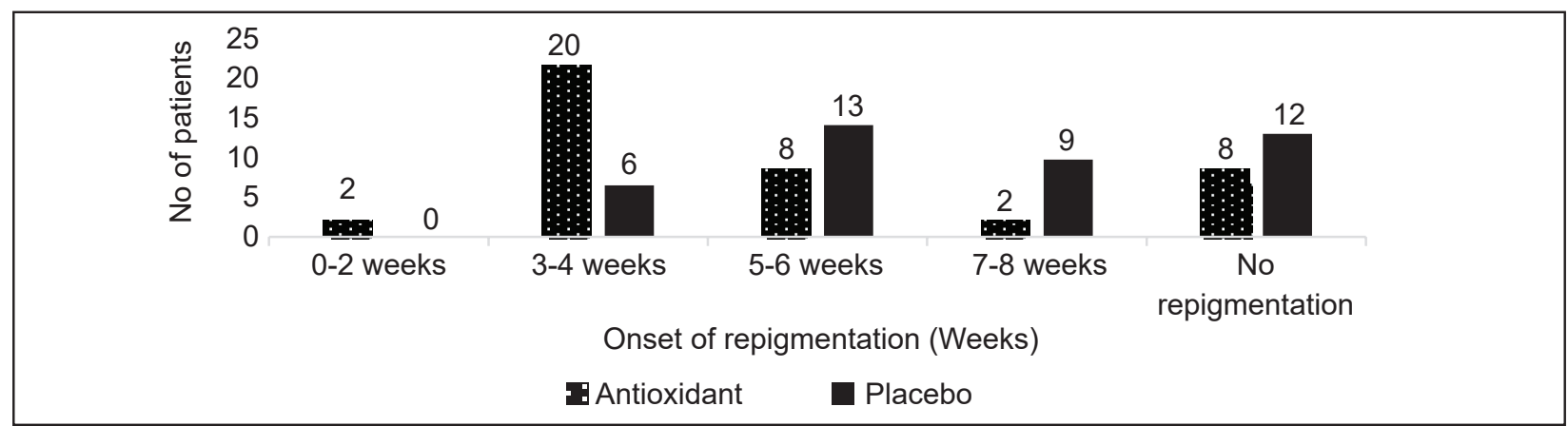

Figure 4: Onset of repigmentation among patients in both the groups.

Table 1: Baseline characteristics among patients in both the groups

\begin{tabular}{|c|c|c|c|}
\hline \multicolumn{2}{|l|}{ Patient characteristics } & Anti- oxidant group & Placebo group \\
\hline \multicolumn{2}{|l|}{ Number of patients } & 40 & 40 \\
\hline \multicolumn{2}{|l|}{ Age in years (mean $\pm S D$ ) (median) } & $33.92 \pm 14.86(31.50)$ & $32.40 \pm 18.38(30.0)$ \\
\hline \multirow{2}{*}{$\begin{array}{l}\text { Sex No. (percentage) } \\
\text { Female }\end{array}$} & Male & $19(47.5 \%)$ & $20(50 \%)$ \\
\hline & $21(52.5 \%)$ & $20(50 \%)$ & \\
\hline \multicolumn{2}{|c|}{ Duration of disease in years (mean $\pm S D$ ) (median) } & $8.76 \pm 8.51(6.0)$ & $6.55 \pm 8.49(5.50)$ \\
\hline \multirow{4}{*}{ Type of vitiligo $\mathrm{N}$ (percentage) } & Focal & $1(2.5 \%)$ & $2(5 \%)$ \\
\hline & Acrofacial & $1(2.5 \%)$ & $2(5 \%)$ \\
\hline & Segmental & $2(5 \%)$ & $1(2.5 \%)$ \\
\hline & Vitiligo vulgaris & $36(90.0 \%)$ & $35(87.5 \%)$ \\
\hline \multicolumn{2}{|c|}{$\begin{array}{l}\text { Body surface area involved in percentage } \\
\text { (mean } \pm \text { SD) (median) }\end{array}$} & $15.18 \pm 20.43(6.0)$ & $8.95 \pm 11.48(6.0)$ \\
\hline \multirow{2}{*}{$\begin{array}{l}\text { Progression } \\
\mathrm{N} \text { (percentage) }\end{array}$} & Progressive & $37(92.5 \%)$ & $32(80 \%)$ \\
\hline & Stable & $3(7.5 \%)$ & $8(20 \%)$ \\
\hline \multirow{3}{*}{$\begin{array}{l}\text { Skin type } \\
\mathrm{N} \text { (percentage) }\end{array}$} & III & $11(27.5 \%)$ & 15 (37.5\%) \\
\hline & IV & $28(70 \%)$ & $24(60 \%)$ \\
\hline & V & $1(2.5 \%)$ & $1(2.5 \%)$ \\
\hline \multirow{9}{*}{$\begin{array}{l}\text { Site involved } \\
\mathrm{N} \text { (percentage) }\end{array}$} & Scalp & $19(47.5 \%)$ & $11(27.5 \%)$ \\
\hline & Face & $19(47.5 \%)$ & $19(47.5 \%)$ \\
\hline & Neck & $19(47.5 \%)$ & $10(25 \%)$ \\
\hline & Trunk & $27(67.5 \%)$ & $22(55 \%)$ \\
\hline & Upper extremities & $28(70 \%)$ & $19(47.5 \%)$ \\
\hline & Lower extremities & $32(80 \%)$ & $27(67.5 \%)$ \\
\hline & Palms & $10(25 \%)$ & $4(10 \%)$ \\
\hline & Soles & $11(27.5 \%)$ & $4(10 \%)$ \\
\hline & Fingers and toes & 9 (22.5\%) & $6(15 \%)$ \\
\hline \multicolumn{2}{|c|}{ Koebner phenomenon [N (percentage)] } & $16(40 \%)$ & $12(30 \%)$ \\
\hline
\end{tabular}


Table 2: Comparison of biochemical parameters levels among anti-oxidant and placebo group.

\begin{tabular}{|c|c|c|c|c|c|c|c|c|}
\hline $\begin{array}{l}\text { Biochemical } \\
\text { Parameters }\end{array}$ & Group & $\begin{array}{l}\text { Baseline [mean } \pm \text { SD } \\
(\mathrm{CI})] \text { (median) }\end{array}$ & $\begin{array}{c}2 \text { months [mean } \pm \text { SD } \\
(\mathrm{Cl})] \text { (median) }\end{array}$ & Difference & t-Test & $p$-value & t- test & $\begin{array}{c}p- \\
\text { value }\end{array}$ \\
\hline \multirow{2}{*}{ MDA } & $\begin{array}{l}\text { Anti- } \\
\text { oxidants }\end{array}$ & $\begin{array}{c}8.40 \pm 2.18(7.71-9.1) \\
(8.18)\end{array}$ & $\begin{array}{c}5.50 \pm 1.41(5.05-5.95) \\
(5.54)\end{array}$ & $2.90 \pm 1.59$ & 11.484 & $<0.001$ & \multirow{2}{*}{11.391} & \multirow{2}{*}{$<0.001$} \\
\hline & Placebo & $\begin{array}{c}7.57 \pm 2.38(6.81- \\
8.33)(6.58)\end{array}$ & $\begin{array}{c}7.55 \pm 2.38(6.79-8.31) \\
(6.52)\end{array}$ & $0.02 \pm 0.09$ & 1.281 & 0.208 & & \\
\hline \multirow{2}{*}{ Vitamin C } & $\begin{array}{c}\text { Anti- } \\
\text { oxidants }\end{array}$ & $\begin{array}{c}0.62 \pm 0.14(0.58- \\
0.67)(0.59)\end{array}$ & $\begin{array}{c}0.55 \pm 0.15(0.50-0.59) \\
(0.53)\end{array}$ & $0.07 \pm 0.06$ & 7.944 & $<0.001$ & \multirow{2}{*}{-0.336} & \multirow{2}{*}{0.738} \\
\hline & Placebo & $\begin{array}{c}0.67 \pm 0.15(0.62-0.72) \\
(0.66)\end{array}$ & $\begin{array}{c}0.59 \pm 0.15(0.55-0.64) \\
(0.58)\end{array}$ & $0.08 \pm 0.07$ & 6.806 & $<0.001$ & & \\
\hline \multirow{2}{*}{ Vitamin E } & $\begin{array}{c}\text { Anti- } \\
\text { oxidants }\end{array}$ & $\begin{array}{c}0.64 \pm 0.21(0.58- \\
0.71)(0.65)\end{array}$ & $\begin{array}{c}0.94 \pm 0.37(0.82-1.06) \\
(0.88)\end{array}$ & $-0.29 \pm 0.28$ & -6.496 & $<0.001$ & \multirow{2}{*}{-6.016} & \multirow{2}{*}{$<0.001$} \\
\hline & Placebo & $\begin{array}{c}0.69 \pm 0.24(0.62- \\
0.77)(0.64)\end{array}$ & $\begin{array}{c}0.70 \pm 0.24(0.63-0.78) \\
(0.63)\end{array}$ & $-0.01 \pm 0.08$ & -0.869 & 0.390 & & \\
\hline \multirow{2}{*}{ CAT } & $\begin{array}{l}\text { Anti- } \\
\text { oxidants }\end{array}$ & $\begin{array}{c}51.69 \pm 23.78(44.09- \\
59.30)(43.45)\end{array}$ & $\begin{array}{c}63.13 \pm 21.89(56.13- \\
70.14)(65.08)\end{array}$ & $-11.44 \pm 16.46$ & -4.395 & $<0.001$ & \multirow{2}{*}{-2.891} & \multirow{2}{*}{0.005} \\
\hline & Placebo & $\begin{array}{c}56.15 \pm 25.84(47.89- \\
64.42)(52.73)\end{array}$ & $\begin{array}{c}56.50 \pm 20.47(49.96- \\
63.05)(54.11)\end{array}$ & $-0.35 \pm 17.82$ & -0.123 & 0.390 & & \\
\hline
\end{tabular}

Table 3: Comparison of stabilization of disease process.

\begin{tabular}{|l|c|c|c|}
\hline Group & $\begin{array}{c}\text { Stabilization } \\
\mathbf{n}(\%)\end{array}$ & $\boldsymbol{\chi}^{2}$ & p-value \\
\hline Anti-oxidant $(n=40)$ & $6(15 \%)$ & 1.13 & 0.288 \\
\hline Placebo $(n=40)$ & $3(7.5 \%)$ & & \multirow{2}{*}{} \\
\hline
\end{tabular}

Table 4: Adverse Effects

\begin{tabular}{|l|c|c|}
\hline Adverse effects & Anti-oxidants (n) & Placebo (n) \\
\hline Pruritus & 0 & 1 \\
\hline Erythema & 5 & 7 \\
\hline Scaling & 1 & 3 \\
\hline Thickening & 3 & 1 \\
\hline Hyperpigmentation & 1 & $\mathbf{1 2}$ \\
\hline Total & $\mathbf{1 0}$ & \\
\hline p value & & 0.786 \\
\hline
\end{tabular}

Among the anti-oxidant group the majority had onset of repigmentation between 3-4 weeks [20 (50.0\%) patients]; whereas among the placebo group majority had repigmentation between 5-6 weeks [13 (32.5\%) patients]. The onset of repigmentation was found to be statistically significantly earlier among the antioxidant group as compared to the placebo group (Log rank test: Ch-Square 5.064 with a $p$ - value of 0.024$)$.
The onset of repigmentation is depicted in Figure 4.

Comparison of cumulative repigmentation at eight weeks

The median value of repigmentation at $8^{\text {th }}$ week was $10 \%$ and $5 \%$ in the anti-oxidant and placebo group respectively, however, this was not found to be statistically significant with a p-value of 0.35 . 


\section{Comparison of oxidant-antioxidant status}

Between anti-oxidants and placebo group

There was no statistically significant difference among the different biochemical parameters in the anti-oxidants and the placebo group at the baseline. However, the level of MDA was found to be significantly lower $(p<0.001)$ and the level of vitamin $E$ and CAT levels were significantly higher ( $p=0.001)$ among the anti-oxidants group as compared to the placebo group at the end of two months. But, no statistically significant difference was found in the vitamin $\mathrm{C}$ level between the two groups (Table 2).

On comparing the oxidant-antioxidant status according to progression, no significant difference was observed between the two treatment groups. Similarly, no significant difference in the stabilization of disease process was observed between the two groups ( $p$-value $=0.294)$. (Table 3 )

\section{Comparison of adverse effects among antioxidants and placebo group}

Adverse effects were seen in eight (20\%) patients of anti-oxidants group and nine $(22.5 \%)$ patients in the placebo group, but the difference was not statistically significant $(p=0.786)$. In our study population, the adverse effects were observed over the photoexposed area. The most common adverse effect was erythema, observed over the photo-exposed area (five in anti-oxidants group and seven in placebo group). No patient required suspension or discontinuation of the therapy for any adverse effects (Table 4).

\section{Discussion}

Numerous treatment modalities have been used for the treatment of vitiligo with variable efficacy but none is a definite treatment. Based on the demonstration of an increased oxidative stress in vitiligo, antioxidants supplementation has been tried alone or in combination with phototherapy for the treatment of vitiligo but with varying responses. ${ }^{11-13,18-22}$

At the baseline biochemical parameters in the antioxidants and the placebo group were comparable. However, at the end of two months the level of MDA among the anti-oxidants group was found to be significantly lower and that of vitamin E and CAT to be significantly higher as compared to the placebo group, but no statistically significant difference was found in the vitamin $C$ between the two groups. This could be due to decrease in the oxidative stress leading to decrease in the MDA level, and increase in CAT and vitamin E level among the patients receiving antioxidant supplementation. Similar to our study, in a randomized trial the CAT levels were found significantly higher among the patients receiving antioxidant supplementation as compared to the placebo group. ${ }^{18}$ They also observed that the intracellular ROS production was decreased in the treated group $(p<0.02)$, whereas it did not change in the placebo group. Elgoweini and colleague observed a significant reduction in the plasma MDA among the patients receiving antioxidants as compared to the patients who did not received antioxidants supplementation. ${ }^{19}$

In general, while some studies show remarkably good results in repigmentation after the use of antioxidants, other studies show no benefits. In the present study, the onset of repigmentation was found to be statistically significantly earlier among the antioxidant group as compared to the placebo group. The earlier onset of repigmentation observed in the anti-oxidant group could be because of the greater decrease in the oxidative stress parameters. This was in concordance with a study where it was found that at two months, patients receiving antioxidant supplementation showed stabilization of disease and partial repigmentation of some of the lesions whereas, patients receiving placebo showed only stabilization of the disease. ${ }^{17}$ Another study conducted with broadband UVB and vitamins [Vitamin C $500 \mathrm{mg}$ twice daily (BD), Vitamin B12 $1000 \mu \mathrm{g}$ BD and folic acid $5 \mathrm{mg} \mathrm{BD}$ ] showed good to excellent repigmentation after 2-8 months of treatment, however they did not assess the levels of different oxidative stress parameters. ${ }^{20}$ Contradictory to the previous studies, Don and associates did not find any significant difference in the repigmentation between the groups receiving combination of antioxidant (containing Vitamin E $25 \mathrm{mg}$, beta-carotene $10 \mathrm{mg}$, vitamin C 100 $\mathrm{mg}$, selenium $75 \mu \mathrm{g}$, copper $1 \mathrm{mg}$, zinc $27.5 \mathrm{mg}$ and manganese $1.5 \mathrm{mg}$ ) with photochemotherapy and photochemotherapy only. ${ }^{20}$ Moreover Tjioe et al also reconfirms that narrow band UVB phototherapy is an effective treatment for vitiligo and shows that cotreatment with vitamin B12 and folic acid does not improve the outcome of treatment of vitiligo with narrow band UVB phototherapy. ${ }^{22}$ In a systematic review, only weak evidence for vitamin $\mathrm{E}$ as an adjunct to phototherapy was found. ${ }^{13}$ Nevertheless, varying dosing of antioxidant might be responsible for varying response.

In our study, stabilization of disease process was seen among six patients in the antioxidants group and among three patients in the placebo group. However, the difference between the two groups was not found to be significant. Higher rate of stabilization among 
the anti-oxidant group could be due to the greater reduction in the redox status. The stabilization was also observed by Dell' Anna et al in the patients receiving antioxidant supplementation. ${ }^{18}$

Erythema was the most common adverse effect observed in both the study group population, however, it was minimal and did not require suspension or discontinuation of the therapy. These adverse effects are most probably due to the sunlight exposure. Similarly, minimal adverse effects were observed in a study by Dell' Anna et al, which did not require suspension or discontinuation of therapy. ${ }^{18}$ In another study, it was noted that mild erythema was less experienced by patients receiving anti-oxidants supplementation rather than those in placebo group. ${ }^{19}$

The major strength of our study is that it is a double blind randomized controlled trial, which assessed the role of antioxidants in the treatment of vitiligo. However, there are a few limitations of the present study: the short duration of follow-up i.e. two months and only few of the oxidative stress parameters could be assessed.

\section{Conclusion}

Antioxidant supplementation carried a better response in terms of early onset of repigmentation and greater decrease in the oxidative stress with well tolerance by the patients. It seems to be a simple, safe and fairly effective therapy for enhancing the onset of repigmentation and arresting the progression of the disease. However, further randomized controlled trials with longer follow-up period and assessment of other oxidative stress parameters are required to measure the oxidative stress in vitiligo and to ascertain the role of antioxidants in the management of vitiligo patients with defined dosing.

Financial disclosure: None

Conflict of interest to disclosure: None declared.

\section{References}

1. Ortonne JP, Bahodoran P, Fitzpatrick TB, Mosher DB, Hori Y. Hypomelanoses and Hypermelanoses. In: Freedberg IM, Eisen AZ, Wolff $K$, Austen KF, Goldsmith LA, Katz SI editors. Fitzpatrick's Dermatology in General Medicine. $6^{\text {th }}$ edition. New York: McGraw Hill 2003.p.839-47.

2. Boissy RE, Spritz RA. Frontiers and controversies in the pathobiology of vitiligo: separating the wheat from the chaff. Exp Dermatol. 2009;18(7):583-5. https://doi.org/10.1111/ j.1600-0625.2008.00826.x

3. Sravani PV, Babu NK, Rao GR, Rao AR, Moorthy B, Rao TR. Determination of oxidative stress in vitiligo by measuring superoxide dismutase and catalase levels in vitiliginous and non-vitiliginous skin. Ind J Dermatol Venereol Leprol. 2009;75(3):268-71. https://doi.org/10.4103/0378-6323.48427

4. Falabella R, Barona MI. Update on skin repigmentation therapies in vitiligo. Pigment Cell Melanoma Res 2008;22(1):42-65. https://doi. org/10.1111/j.1755-148X.2008.00528.x

5. Agrawal S, Kumar A, Dhali TK, Majhi SK. Comparison of Oxidant-Antioxidant Status in Patients with Vitiligo and Healthy Population. Kathmandu Univ Med J 2014;46(2):132-6. https:// doi.org/10.3126/kumj.v12i2.13660

6. Laddha NC, Dwivedi M, Mansuri MS, Gani AR, Ansarullah M, Ramachandran AV et al. Vitiligo:

interplay between oxidative stress and immune system. Exp Dermatol 2013 22: 245-50. https:// doi.org/10.1111/exd.12103

7. Picardo $M$, Grammatico P, Roccella $F$, Roccella M, Grandinetti M, Del Porto G et al. Imbalance in the antioxidant pool in melanoma and normal melanocytes from patients with melanoma. J Invest Dermatol. 1996;107(3):322-6. ttps://doi. org/10.1111/1523-1747.ep12363163

8. Schallreuter KU, Moore J, Wood JM, Beazley WD, Gaze DC, Tobin DJ et al. In vivo and in vitro evidence for hydrogen peroxide $\left(\mathrm{H}_{2} \mathrm{O}_{2}\right)$ accumulation in the epidermis of patients with vitiligo and its successful removal by a UVB-activated pseudocatalase. J Investig Dermatol Symp Proc. 1999;4(1):91-6. https://doi.org/10.1038/sj.jidsp.5640189

9. Taieb A. Intrinsic and extrinsic pathomechanisms in vitiligo. Pigment Cell Res. 2000;13(8):41-7. https://doi.org/10.1034/j.1600-0749.13.s8.9.x

10. Schallreuter KU, Moore J, Wood JM, Beazley WD, Peters EMJ, Marles LK et al. Epidermal $\mathrm{H}_{2} \mathrm{O}_{2}$ accumulation alters tetrahydrobiopterin $(6 \mathrm{BH} 4)$ recycling in vitiligo: Identification of a general mechanism in regulation of all $6 \mathrm{BH} 4-$ dependant processes? J Invest Dermatol 2001; 116(1):167-74. https://doi.org/10.1046/j.15231747.2001.00220.x

11. AkyolM, Celik VK, Ozcelik S, Polat M, Marufihah $M$, Atalay $A$. The effects of vitamin $E$ on the skin 
lipid peroxidation and the clinical improvement in vitiligo patients treated with PUVA. Eur J Dermatol 2002;12(1):24-6.

12. Patel DC, Evans AV, HawkJL. Topical pseudocatalase and narrowband UVB phototherapy is not effective for vitiligo: an open, single centre study. Clin Exp Dermatol. 2002;27(8):641-4. https://doi. org/10.1046/j.1365-2230.2002.01142.x

13. Szczurko O, Boon HS. A systematic review of natural health product treatment for vitiligo. BMC Dermatol. 2008;8: 2. https://doi. org/10.1186/1471-5945-8-2

14. Yagi K. Lipid peroxides and human diseases. Chem Phys Lipids 1987;45(2-4):337-51. https://doi. org/10.1016/0009-3084(87)90071-5

15. Sullivan MX, Clarke HCN. Estimation of Ascorbic Acid. J Assoc of Agric Chem. 1955;38:514-5.

16. Bieri JG, Teets I, Belavculy B, Andrews EL. Serum Vitamin $E$ levels in a normal adult population in Washington DC Area. Proc Soc Exptl Biol Med 1964;117:131-3. https://doi. org/10.3181/00379727-117-29515

17. Sinha AK. Colorimeter Assay of Catalase. Anal Biochem. 1972; 47(2): 389-94. https://doi. org/10.1016/0003-2697(72)90132-7
18. Dell'Anna ML, Mastrofrancesco A, Sala R, Venturini $\mathrm{M}$, Ottavani $\mathrm{M}$, Vidolin $\mathrm{AP}$ et al. Antioxidants and narrow band-UVB in the treatment of vitiligo: a double blind placebo controlled trial. Clin Exp Dermatol. 2007;32(6):631-6. https://doi. org/10.1111/j.1365-2230.2007.02514.x

19. Elgoweini $M$, Din NNE. Response of vitiligo to narrowband ultraviolet $B$ and oral antioxidants. J ClinPharmacol. 2009;49(7):852-5. https://doi. org/10.1177/0091270009335769

20. Don P, luga A, Dacko A, Hardick K. Treatment of vitiligo with broadband ultraviolet $B$ and vitamins. Int J Dermatol 2006;45(1):63-5. https://doi. org/10.1111/j.1365-4632.2005.02447.x

21. Jayanth DP, Pai BS, Shenoi SD, Balachandran C. Efficacy of antioxidants as an adjunct to photochemotherapy in vitiligo: A case study of 30 patients. Ind J Dermatol Venereol Leprol. 2002;68(4):202-5.

22. Tjioe $M$, Gerritsen MJP, Juhlin L, van de Kerkhof PCM. Treatment of Vitiligo Vulgaris with Narrow Band UVB $(311 \mathrm{~nm})$ for One Year and the Effect of Addition of Folic Acid and Vitamin B12. Acta Derm Venereol. 2002;82(5):369-72. https://doi. org/10.1080/000155502320624113. 